This is a post-print version of the following article: Vargas-Urpi, Mireia (2013). Coping with nonverbal communication in public service interpreting with Chinese immigrants. Journal of Intercultural Communication Research, $42 \quad$ (4), 340-360. (DOI:10.1080/17475759.2013.838985)

\title{
Coping with nonverbal communication in public service interpreting with Chinese immigrants
}

\author{
Mireia Vargas-Urpi
}

\begin{abstract}
Nonverbal communication (NVC) plays a key role in face-to-face interactions. This article explores how nonverbal communication affects interpreter-mediated interactions between Chinese immigrants living in Catalonia and local public service providers. It presents data obtained from a qualitative study based on in-depth interviews with public service interpreters and intercultural mediators, and analyses their experience in coping with nonverbal cues that are the potential source of misunderstanding. Special attention is given to the examples of the Chinese smile and absence of eye contact. The conclusions discuss the implications that nonverbal communication may have in defining the role and functions of public service interpreters.
\end{abstract}

Keywords: nonverbal communication, public service interpreting, community interpreting, intercultural communication, intercultural mediation

\section{Introduction}

Public service interpreting (PSI) consists of face-to-face interactions where at least two of the participants come from different cultures: local public service providers (doctors, nurses,

\footnotetext{
* This paper has been supported by the Universitat Autònoma de Barcelona with a PIF grant. It is also part of the Research, Development and Innovation (RDI) projects funded by the Spanish Ministry of Education: El impacto de Asia Oriental en el contexto español: Producción cultural, política(s) y sociedad” (FFI2011-29090) and “Inter-Àsia. Grup de recerca interdisciplinari d'estudis d’Àsia oriental” (2009 SGR 1103) of the Inter-Asia research group.

Mireia Vargas-Urpi is a member of the MIRAS, InterAsia and TXICC research groups in the Department of Translation and Interpreting, Universitat Autònoma de Barcelona. Correspondence should be sent to Mireia Vargas-Urpi, Facultat de Traducció i Interpretació, Universitat Autònoma de Barcelona. Campus de Bellaterra, Cerdanyola del Vallès, 08193 Spain. Email: mireia.vargas@uab.cat
} 
teachers, lawyers, judges, etc.), and migrant users who do not speak the official languages of the host country. Research on PSI has mainly focused on the analysis of verbal utterances in this kind of interaction (Wadensjö, 1998; Cambridge, 1999; Bolden, 2000; Davidson, 2000; Hale, 2000, 2001; Mason \& Stewart, 2001; Angelelli, 2004; Pöllabauer, 2004, 2006; Baraldi, 2009; Cirillo, 2010, amongst others), while scarce attention has been paid to the role of nonverbal communication (NVC) from an intercultural perspective or to the strategies interpreters employ when dealing with culturally different nonverbal cues. Research on PSI which does include NVC aspects has explored the influence of the interpreter's location in a triadic exchange (cf. Wadensjö, 2001) or the transmission of emotions in a medical interview (Iglesias Fernández, 2010).

If NVC is taken as being culturally conditioned, we could well expect NVC differences to come to the surface and to influence the participants' perception of the Other in this kind of intercultural encounter. In this regard, interpreters and mediators can play a crucial role in smoothing out the difficulties posed by differences in NVC patterns, since they are the only participants who may know how both cultures behave nonverbally. Hence, by focusing on the study of interpreters' views on and concerns with NVC and, by extension, on the role of the "person in the middle", this article attempts to add a new perspective to intercultural communication research.

In Catalonia, the Chinese immigrant population ranks fifth as a foreign community, with 49,612 registered citizens in 2012. Notable increases in this community started in the 1990s and rose considerably during the first decade of the $21^{\text {st }}$ century: from 4,461 citizens in 2000 to 46,333 in 2010. ${ }^{1}$ Most Chinese have arrived without any knowledge of Catalan or Spanish, the official languages in Catalonia. Nevertheless, they need to contend with different

\footnotetext{
${ }^{1}$ Data from Idescat, the Catalan Statistics Institute. URL: http://www.idescat.cat/ (accessed $6{ }^{\text {th }}$ June 2013). For a more detailed description of Chinese immigration in Catalonia see Beltrán Antolín and Sáiz López (2001) and Beltrán Antolín (2009).
} 
kinds of public services in their everyday life: register their children at school, apply for various public services (e.g. the health card), visit a doctor or report an incident to the police. In short, intercultural communication with Catalan public services is a reality.

NVC in the Chinese culture is basically different from that in Catalonia, where gestures are widely used in face-to-face interactions, particularly hand gestures, head nods, eye contact and reactive tokens. Moreover, given that NVC constitutes up to $93 \%$ of communication (see Wood, 2013, for specific references), especially when it comes to the believability of the message, intercultural communication and misinterpretation is bound to occur because the Chinese immigrant population is growing in Catalonia and Chinese culture places emphasis on saving face and creating harmony. These questions are addressed in more detail later in this article.

Therefore, the aim of this article is to shed light on the role of NVC in intercultural encounters between Catalan public service providers and Chinese users of these services. First, it presents a review and discussion of the previous research on NVC in Chinese culture. Second, it sets out the objectives and the qualitative methodology used in this study. Third, it describes the sample of informants and then presents and analyses the information obtained from the interviews. Finally, the conclusions stress the importance of face (mianzi) in NVC and discuss the challenges that NVC poses for the public service interpreters.

\section{Previous research}

Nonverbal communication has attracted considerable interest from a number of different disciplines in recent years, and has been studied from many different perspectives and for many different purposes.

Hickson, Stacks and Moore (2004:7) stress that most researchers agree that NVC 
corresponds to approximately two thirds of the information transmitted in a face-to-face interaction (60\%-70\%), as also noted by Birdwhistell (1970) and Philpott (1983). Moreover, NVC plays a critical role in interpersonal interactions. It is perceived as more believable than verbal communication when the two are incongruent (Mehrabian, 1981; Malandro \& Barker, 1983; Guerrero \& Floyd, 2006; Knapp \& Hall, 2007; Wood, 2013) and this can clearly affect the interpersonal relationship established between the participants in a face-to-face conversation.

Traditionally, NVC has been classified into the following categories: proxemics, haptics, physical appearance, kinesics, vocalics and chronemics (Hickson et al., 2004; Wood, 2013).

Proxemics refers to the study of the physical distance between people when they interact. This term was coined by Hall (1976), who pointed out three types of proxemics: intimate distance (interactions with relatives), personal distance (interactions with close friends), and social distance (impersonal interactions). These distances may also be influenced by other factors such as age, gender, culture or social status.

Haptics consists of the study of contact (or absence of space) between two people. Physical contact between two people may have different functions, which may vary from culture to culture. For instance, in Catalonia, a handshake is a common greeting in formal situations, while kissing both cheeks is preferred in informal situations involving a man and a woman or two women.

Physical appearance ranges from physical qualities such as height, hair or physical attractiveness to modifiable conditions such as dress codes.

Kinesics refers to the study of physical movements and gestures, including facial expressions. Western cultures, including the Catalan culture, may use a nod of the head or eye-contact to show responsiveness towards the speaker. In contrast, eye-contact may be 
considered rude in some traditional Asian societies (Wood, 2013:21).

Vocalics consists of the study of information that may be transmitted by means of the voice: intonation, pitch, length, articulation and silences. Finally, chronemics refers to the study of the impact time may have on our communication and how different cultures may have different perceptions of time.

\subsection{Intercultural communication with the Chinese}

It would be appropriate at this point to contextualize studies which focus on Chinese patterns of NVC to those carried out in the field of intercultural communication. Since Hofstede's (1980, 1991) contribution, Chinese culture has been described as a collectivist culture, i.e. a culture which gives priority to the group's interests over the individual's. People try to preserve harmony within the group and, therefore, they display a high degree of concern about conflict avoidance (Raga, 2003). This can be seen in the strategies used to avoid losing face (mianzi, 面子).

Face is a key element to understand Chinese verbal and nonverbal communication patterns (Hu, 1944; Hwang, 1987; Gao, 1998). According to Hu (1944), face refers to the image projected to the others and to one's reputation achieved through life. It can be lost if certain courtesy rules are not followed (e.g. if an invitation is not accepted), but it can also be given (e.g. when accepting the invitation, face is given to the inviting person). In general, the Chinese as a collectivist society try to promote harmony by avoiding any kind of situation that would make oneself or the other lose face, either by means of verbal strategies, but also nonverbally, as will be shown later.

Collectivist cultures also tend to involve high power distance, i.e., hierarchical differences amongst people are accepted and strictly respected (Hofstede \& Hofstede, 2005). 
At the other end of the spectrum, Hofstede and Hofstede place cultures such as in the USA, UK or New Zealand, as clear examples of individualist, low power distance cultures.

While Hofstede and Hofsted (2005) emphasize collectivism and high power distance in their description of Chineseness, Hall (1976) proposes the idea of "high context communication” to describe Asian cultures such as the Chinese or Japanese. In high context communication, "most of the information is already in the person, while very little is in the coded, explicitly transmitted part of the message” (Hall, 1976:91). The opposite is the case for "low context communication" cultures, such as the German culture, where most of the information is placed in the explicit code. ${ }^{2}$ In the case of the Chinese, NVC may perform an important role in this kind of indirect and implicit communication, where a silence or a gesture may mean more than the information conveyed by words.

\subsection{NVC in Chinese communication patterns}

Bearing in mind the acknowledged importance given to NVC, one may well expect that there would be an abundance of research on the meanings of different nonverbal cues between cultures. In practice, however, although there has been research on this field, on many occasions it has been based more on personal perceptions or intuitions, than on experimental or evidence-based studies. In the following list, the main contributions dealing with Chinese NVC are reviewed and classified according to the domains presented in the first section.

\subsubsection{Kinesics}

This is one of the domains where there has been more research. Smile and gaze are two of the most studied nonverbal cues, as well as specific hand gestures.

\footnotetext{
${ }^{2}$ For more information on Chinese communication patterns, see Triandis, Brislin and Hui (1988), Bond (1991, 1993), Gao (1998) and Gao and Ting-Toomey (1998).
} 
Different meanings have been attributed to the Chinese smile or laugh, as in Chinese, xiao (笑) may refer to either smile or laugh. Bi (1998:127) explains that the Chinese smile does not always denote happiness or cheerfulness, which can lead to misunderstanding in interactions between Chinese and Western cultures. Bi (1998:28) supports the view that the Chinese gentle smile, weixiao (微笑), appears in a great variety of situations: to express that the speaker's good intentions have been understood, to convey admiration, disagreement, disdain, that something has not been understood or even that something has not been heard. It can also mean that something is being evaded, that the situation is uncomfortable or that the speaker does not want to detail what s/he is saying (Chen, 1987:175). Therefore, we could assume that it is an extremely versatile sign that may appear in unexpected situations from the point of view of the Western speaker, and that may surprise interlocutors if they do not share these communicative conventions.

Sun (2010) suggests the following classification for the Chinese smile:

a) Compensating smile or peixiao (赔笑): the kind of smile used to re-establish harmony in a difficult or uncomfortable situation and "to reduce interpersonal unpleasantness” (Sun, 2010:111). Sales Salvador (2003:125) also mentions this kind of smile.

b) Bitter smile or kuxiao (苦笑); a kind of smile that shows the speaker's good feelings in a frustrating situation, in which s/he feels powerless. It is a forced smile that tries "to suppress the display of bad feelings by portraying good feelings through facial expressions” (Sun, 2010:113).

According to Sun (2010:114-116) both kinds of smiles are two strategies to preserve the harmony in relationships (hexie guanxi, 和谐关系), which is also often achieved by being implicit and contained (hanxu, 含蓄). 
However, Yang (2007:1) points out that the gentle smile (weixiao, 微笑) may also be used by participants to "demonstrate their connection and closeness to each other". In more specific terms, according to Yang, the gentle smile is used by the hearer to show: a) that s/he is listening to the speaker, or b) that s/he feels empathy or sympathy towards the speaker. Yang bases this premise on NVC playing a crucial role in collectivist cultures, as well as in high-context communication patterns (such as the Chinese), since NVC is used to display affiliation and high involvement in conversation. Yang includes other nonverbal cues in her study: gaze (zhushi, 注视), head nods (diantou, 点头) and hand touch (shouchu, 手触).

In short, Bi (1998) supports the view that the Chinese smile can be used in a great variety of situations; Sun (2010) distinguishes between the compensating smile and the bitter smile -both used in difficult or uncomfortable situations; and Yang (2007) defines the gentle smile as an affiliative strategy in a conversation.

Eye contact in Chinese culture has also been subject to different explanations. On the one hand, Bi (1998:26) and Sales Salvador (2003:125-126) state that, in a conversation, the Chinese usually try to avoid direct eye contact with their interlocutor, as a sign of respect, courtesy and obedience. This contrasts with Western cultures, where lack of eye contact may be a sign of lack of attention, interest or honesty. On the other hand, Yang (2007:25) sustains that gaze (zhushi, 注视) is used by Chinese interlocutors to “implement interactive attentiveness, conduct mutual monitoring and regulate interaction in conversations.” In a subsequent contribution, Yang explains the different functions of gaze and non-gaze: while gaze is used by the listening party to demonstrate their eagerness to take up a turn in a conversation (2011:111), non-gaze or gaze-away (bianshi, 边视) is used by the speaking party to keep their turn in a conversation, especially in a pause when searching for a word or an expression (2011:121-122). 
Still in the domain of kinesics, specific ritualized gestures have been explained, such as counting with fingers - only with one hand - for numbers from 1 to 10 (Bi, 1998:34); pointing at someone not with the forefinger, but with an open hand (Axtell, 1998:179); giving a business card with both hands or etiquette codes related to meals (Axtell, 1998:180), amongst others. As far as these kinds of gestures are concerned, one of the most illustrative contributions is Torres Sánchez’s (2010) catalogue of Chinese-Spanish nonverbal signs. In her comparative study, Torres Sánchez classifies the signs according to their function and distinguishes the following categories: signs used with communicative functions (similar to emblems), signs used with social functions (greeting, thanking, congratulating, etc.) and signs used with discursive functions (asking the interlocutor to speak slowly). The author describes each sign by means of pictures and shows how the same meaning is conveyed by different signs according to Chinese and Spanish nonverbal patterns. For instance, some of the Chinese signs she includes are pointing at one's own nose, meaning “it's me”; pointing at one's own head, used to describe someone as stubborn; or tapping at one's own pocket, used to describe someone as rich.

\subsubsection{Haptics and proxemics}

Haptics and proxemics are closely related domains, since both of them focus on the distance or absence of distance between people.

According to Axtell (1998) and Bi (1998), the Chinese do not usually touch, hug or kiss each other when greeting. Axtell points out that even though the Western convention of shaking hands is extending throughout China, very often just a slight head bow is enough. Torres Sánchez (2010:84) states that, while shaking hands is more frequent between men, it is 
often avoided when a man greets a woman. Bi (1998) notes that, when shaking hands, the Chinese often bow forwards slightly to show respect.

As far as touching others is concerned, Yang $(2007,2011)$ describes the hand touch between interlocutors as an affiliative device and as a strategy to take up a turn in a conversation. However, Torres Sánchez (2010:84) explains that there is very scarce physical contact between men and women in public in China.

Regarding proxemics, Axtell (1998) states that the Chinese tend to get closer to their interlocutor when talking to them, possibly due to the limited personal space in China. In contrast, Sales Salvador (2003), quoting Ramsey (1984), sustains that the distance between Asian people (e.g., Chinese, Japanese) in interaction tends to be greater. As can be seen, previous studies on haptics and proxemics are scarce and contradictory, a fact that underlines the need for more research on these areas.

\subsubsection{Paralanguage (vocalics)}

Concerning paralanguage, Sales Salvador (2003) presents one of the most comprehensive reviews of the state of the art and, in her study, works from the following hypotheses: ${ }^{3}$

- Interturn pauses tend to be longer than in Western cultures (Scollon \& Scollon, 1995:63). Axtell (1998) also highlights that "silence is a virtue". This may also be a feature of highcontext communication, where silences may convey specific meanings.

- Reactive tokens are scarce. Reactive tokens refer to "short utterances produced by an interlocutor who is playing a listener's role” while the other interlocutor is speaking (Clancy, Thompson, Suzuki \& Tao, 1996:355). However, Bi (1998:47) notes that Chinese listeners tend to show that they are listening and following their interlocutor's

\footnotetext{
${ }^{3}$ Sales Salvador (2003: 123) bases her hypotheses on the following contributions: Ramsey, 1984; Young, 1994; Scollon and Scollon, 1995; Clancy, Thompson, Suzuki and Tao, 1996; Raga and Sánchez, 1999; and Raga, 2005.
} 
words nodding their head and saying $n g$ 'ng (嗯嗯), ${ }^{4}$ an unarticulated velar sound that has been attributed different uses. According to $\mathrm{Bi}$, it is only used to let the other know that they are being listened to, a function that may be confusing to North-American interlocutors, since they tend to relate this sound to agreement with the other's words. On the other hand, Yang (2007) states that head nodding (diantou, 点头) combined with unarticulated sounds are used by the Chinese to show agreement. The Contemporary Chinese Dictionary (Xiandai Hanyu Cidian, 现代汉语词典), also attributes agreement to ng, similar to ‘yeah’ in English.

- Overlapping between interlocutors is scarce. Interlocutors tend to avoid interrupting each other or talking at the same time. According to Axtell (1998), this is clearly related to interturn pauses and silences in a conversation, while Bi (1998) points out that it is a sign of respect and active listening (tinghua, 听话). Gao (1998) includes tinghua (听话) as one of the usual practices developed in Chinese communication. Although Gao (1998:172) translates tinghua as "listening-centeredness", it is often translated as "listening” or "being obedient”, which clearly separates the roles of speaker and listener. In the case of the listener, silence, attention and obedience are highly valued, especially if the speaker is a person of a higher status. Since it refers to a way of behaving, in this paper we use the concept "active listening”

- $\quad$ Paralinguistic emphasis is low: low voice volume and slow tempo.

This low paralinguistic emphasis or lack of expressiveness is also perceived in relation to physical pain. For instance, Raga (2009) points out that Chinese women do not usually

\footnotetext{
${ }^{4} \mathrm{Bi}$ (1998) refers to $n g$ ’ng (嗯恩) in fourth tone. It is also pronounced in second tone to indicate question or doubt, and in third tone to indicate surprise.
} 
express a lot of pain when giving birth, a feature which is also found in other cultures, such as the Hmong (Fadiman, 2012).

In conclusion, the studies reviewed in this section describe a cultural group where an important emphasis is placed on concealing one's emotions, as opposed to self-expression, direct talk or direct eye contact. This is common in collectivist societies and is considered a way of promoting harmony.

\section{Our study}

This article is a contribution that stems from the research developed in Vargas-Urpi's (2012) dissertation: La interpretació als serveis públics i la mediació intercultural amb el col·lectiu xinès a Catalunya (Public service interpreting and intercultural mediation with the Chinese in Catalonia). Its main objective was to describe and analyse PSI and intercultural mediation for the Chinese in Catalonia from a broad perspective, especially taking into account that both professional practices are a recent development in Catalonia.

According to previous research, NVC can play an important role in intercultural communication, yet scarce attention has been paid to the role of NVC in PSI training and research. Therefore, the aim of this article is to take stock of the awareness among public service interpreters and intercultural mediators concerning the role of NVC in PSI. In more specific terms, it attempts to assess to what extent NVC is perceived as a difficulty by public service interpreters and intercultural mediators working with the Chinese community in Catalan public services. It also attempts to identify what specific nonverbal cues are more often regarded as a barrier in intercultural communication in Catalan-Chinese mediated interactions.

\subsection{Method}


With these objectives in mind, a qualitative method was chosen. Data collection consisted of interviews with twenty public service interpreters and intercultural mediators working with the Chinese community in Catalonia. As part of a larger research project, interviews covered a wide range of topics concerning PSI and intercultural communication with the Chinese. For instance, some questions referred to interpreters' training and experience, or to the linguistic difficulties they encountered when interpreting between Chinese and Catalan. However, this paper will only focus on information related to NVC.

Interviews took place between March and October 2010. They were informal and semistructured, i.e. even though there was a list of questions and topics to be covered during the interviews, it was not a fixed guide, and could be adapted to interviewees' answers. New questions could be added and the order of questions could be changed if, as interviewers, we felt it could help us get additional or relevant information.

Interviews were recorded and transcribed verbatim. These transcriptions were then analysed by means of Atlas.ti, software for qualitative data analysis. Atlas.ti's interface displays the transcription and excerpts can be selected and assigned codes. These excerpts can then be retrieved and classified according to these codes.

Qualitative content analysis (Mayring, 2000) was applied for the analysis of the corpus of transcriptions. It was used to assign codes and develop a formative analysis (inductive and deductive), since some codes were related to our objectives and foreseen in the interview guides. Some codes, however, were totally unexpected from the point of view of our research approach, but they were nevertheless deemed important to describe the object of study. The codes reflected the categories that will be discussed later on, namely, Chinese lack of expressiveness, smile, lack of eye contact, etc.). These were used to classify the answers collected from the informants. 


\subsection{Limitations of the present study}

The main limitation of the present study is not having dealt with data obtained from direct observation of interactions. Even though this was considered, it was dismissed due to time constraints and lack of adequate technical equipment. Another limitation is not having contrasted the views of interpreters and mediators with those from local public service providers and Chinese users who take part in this kind of mediated interactions. Finally, another limitation of the study is the limited number of interviews, meaning the findings cannot be generalized. However, despite these limitations, analysing the perceptions of interpreters and mediators can give us an idea of how these professionals regard intercultural communication and the role of NVC in these intercultural interactions.

\section{The sample of informants}

All those interviewed were interpreters or intercultural mediators working in Catalan public services at the moment of the interview. Fifteen of them were women, while five were men. This breakdown is frequent in the field of PSI (Arumí, Gil-Bardají \& Vargas-Urpi, 2011), which has been described as a feminized profession.

Concerning their origin, twelve interviewees were Chinese, seven were European and one was from Latin America (see table 1).

Table 1. Origin of Informants

\begin{tabular}{|l|l|l|}
\hline \multicolumn{1}{|c|}{ Origin } & \multicolumn{1}{|c|}{ Place of birth } & \multicolumn{1}{|c|}{$\begin{array}{c}\text { Reason for going to Catalonia } \\
\text { (those of Chinese origin) }\end{array}$} \\
\hline Chinese & Zhejiang (4), Fujian (2), Shanghai (1) & Immigration \\
\cline { 2 - 3 } & $\begin{array}{l}\text { Jiangsu (2), Beijing (1), Shandong (1), } \\
\text { Taiwan (1) }\end{array}$ & University studies \\
\hline Non-Chinese & $\begin{array}{l}\text { Catalonia (5), other regions in Spain (1), } \\
\text { France (1), Latin America (1) }\end{array}$ & \\
\hline
\end{tabular}


Amongst the twelve Chinese, seven of them migrated to Catalonia with their parents when they were still children or teens, and five of them went there to further their studies. All the informants had been living for some time in the other country (China or Catalonia), even though the length of this stay varies among the informants: from one year to more than fifteen years.

Nineteen of them had university degrees: four in Translation and Interpreting and six in Sinology or East Asian Studies; while the other informants came from a range of university backgrounds (Medicine, Law or Politics, among others). Eight of them had received informal training in Intercultural Mediation, where issues related to intercultural communication are often included as part of the curriculum.

The informants' experience as public service interpreters or intercultural mediators was also varied: five of them had been working in this field for less than one year, while four of them had been interpreters or mediators for five to ten years. In terms of working profile, seven worked full-time, five had part-time contracts and eight were freelance, working occasionally.

In short, the sample of interviewees was extremely heterogeneous, a fact that reflects the diversity inherent in professional PSI and intercultural mediation. This heterogeneity also needs to be considered when examining the various answers received from informants.

\section{NVC from the point of view of interpreters and mediators}

The interviews covered different topics concerning public service interpreting and intercultural communication with the Chinese. The objective of the first question on NVC was to ascertain the overall perception of the informants concerning the role NVC plays in intercultural encounters in which they act as interpreters or mediators. Five of them report 
that "it is not so important", among which informant 8 explains that, since he has lived for a long time in China, this may have influenced his perception of NVC and, therefore, he does not pay much attention to NVC (INF8, 40:44, male, Catalan interpreter; personal communication, April 29, 2010).

Nine interviewees agree on the fact that "Chinese are rather inexpressive". Even though their overall feeling is that being inexpressive reduces the impact of NVC in an interaction, this kind of answer already points to a specificity of Chinese NVC patterns and, particularly, that it is closely related to paralanguage and kinesics. On this issue, informant 18 explains that the lack of reactive tokens in Chinese feedback sometimes makes him wonder if the message (once interpreted) has been understood or not: "For instance, you're talking to me and maybe I make some kind of sign to let you know I'm following you. They don't! They just stay like this [still], without moving. But, then, you don't know if they are getting your message or not” (INF18, 31:56, male, Latin American interpreter; personal communication, November 16, 2010). ${ }^{5}$

This description reinforces one of the features Clancy et al. (1996) and Sales Salvador (2003) stress in their studies: reactive tokens are scarce in Chinese interactions. It is related to active listening (Gao, 1998), especially evident when there is also power distance between participants. From the perspective of the relevance theory (Sperber \& Wilson, 1995), the lack of visible feedback from the Chinese interlocutor leaves the interpreter with the uncertainty of whether the intended ostension of her/his message has been inferred by the Chinese.

Informants 7 and 9 also refer to the lack of expression of feelings by the Chinese and, in both cases, it is almost regarded as a negative feature. Informant 7 explains that "When parents are told bad news, many of them, just remain like impassive! As if their children

\footnotetext{
${ }^{5}$ Original excerpts are in Spanish or Catalan and have been translated into English by the author. The original excerpts may be consulted in Vargas-Urpi (2012).
} 
weren't theirs!” (INF7, 39:83, female, Chinese interpreter; personal communication, April 26, 2010). Informant 9 just describes the Chinese as “inscrutable” (INF9, 41:47, male, Catalan interpreter; personal communication, May 5, 2010).

On the other hand, informant 11 is more relativistic on this topic and explains that, even though communication is mostly verbal, the Chinese are gradually getting used to the gestures that doctors make; for instance, the gesture made with a hand meaning 'to eat'. However, she stresses that body language is not really relied on in this kind of interaction.

In contrast, twelve informants do think that certain nonverbal cues need explaining, since they may transmit different meanings in the cultures in interaction (Catalan and Chinese). Amongst them, six informants mention the specificities of the Chinese smile (Bi, 1998; Sales Salvador, 2003; Sun, 2010) and six refer to the lack of eye contact (Bi, 1998; Sales Salvador, 2003; Yang, 2007). The lack of physical contact when greeting (as opposed to the two kisses in Catalonia) and the lack of hand touch in the school environment are also pinpointed.

\subsection{The Chinese smile}

Regarding the smile or laugh, from the point of view of a Catalan interlocutor, the smiles that may be more puzzling are the compensatory smile (peixiao, 赔笑) and the bitter smile (kuxiao, 苦笑), as they convey different reactions to those expected in the context where they appear. Some informants explain that these kinds of smile have been the cause of awkward situations. Informant 18 , who works as a court interpreter, ${ }^{6}$ recalls a situation where he had to intervene to explain the meaning of a Chinese smile in order to solve a misunderstanding that was worsening precisely because of that smile:

\footnotetext{
${ }^{6}$ It must be noted that the interpreters' own interventions are extremely restricted in court and police settings.
} 
They laugh. Of course, if they see something funny, they laugh; but [when] they are in a difficult situation, they laugh. But, of course, a Spanish person that doesn't know that... Once, a judge got really mad at a Chinese woman, because while the Chinese was being told off by the judge, she [the Chinese] was laughing. That Chinese woman came with a baby and the baby was crying, so the judge told her not to bring a baby; she told her that people don't bring babies to a hearing. And she [the Chinese woman] started to laugh. The judge was going red [in anger]... and well, at that moment, I told her [the judge] that the Chinese woman was laughing because she was in a difficult situation, even though that may sound contradictory. If you're in a difficult situation, you won't laugh, because your culture doesn't let you laugh; but when they [the Chinese] are in a difficult situation, they laugh. (INF18, 31:55; male, Latin American court interpreter; personal communication, November 16, 2010)

For informant 17, the smile or laugh is the nonverbal cue that causes most misunderstandings. She recalls a similar experience, in which a compensatory smile from a Chinese man irritated a public service provider, who did not understand why he was smiling:

The biggest problem, the gesture that causes the biggest problems -and I still can't explain it well-, is the laugh, the smile. Once, there was a social worker who got really angry because of a smile! He even wanted to call the police, really, during the interview. He was saying, "He's laughing! He’s even laughing!” Well, they can have really strong reactions to a Chinese smile. But I also notice that... a Chinese smile can mean so many things! It could mean "I agree with you”, but it could also mean “I don’t understand you, but I’ve been listening to you”. I don’t know; it can mean so many things that it isn’t easy to explain. But, well, the first is: "Please, don't be misguided, that smile isn't intended to offend you," even though sometimes it can really be misunderstood. In some interviews, I tell the providers: “Talk to [the Chinese user]. So 
she understands you” and they answer: "But, she’s laughing all the time! How can I know whether she's understood me or not.” Yes, it's something that also makes me think. (INF13, 30:73, female, Chinese mediator; personal communication, November 12, 2010).

Informant 17 is aware of the different meanings attributed to the Chinese smile and, in this excerpt, she talks about situations in which the three kinds of smile explained in the second section are referred to. Since she works as a mediator, she can give some warning about the differences in the meaning of a smile in the Chinese and Catalan cultures, even though that is not easy because of the various meanings the Chinese smile may convey. While interpreters are expected to adopt a more impartial role and to limit their interventions in an interpreted conversation, mediators are allowed more flexibility to intervene and provide cultural clarifications. $^{7}$

Informants 2 and 4 also explain that they are gradually making their colleagues (public service providers) aware of these differences. For instance, informant 2 often tells her colleagues that the Chinese smile is like "a courtesy sign, even if they feel terrible (...). It's like a smile that avoids conveying any emotion; that avoids transmitting any uncomfortable feeling” (INF2, 33:15, female, Spanish mediator; personal communication, April 15, 2010). This example reflects how mediating activities with providers may increase their sensitivity towards issues concerning intercultural communication and, more specifically, NVC.

Informant 3 relates the Chinese smile to Chinese inexpression, since smiling helps a Chinese avoid showing anger: “you may feel they're angry, but not in their [facial] expression, since it really shows self-control” (INF3, 35:86, female, Catalan mediator; personal communication, April 20, 2010). This example is clearly related to Sun's (2010) bitter smile, but also to the high degree of concern about conflict avoidance (Raga, 2003)

\footnotetext{
${ }^{7}$ See Vargas-Urpi (2012 and 2013) for further information on their different roles and functions.
} 
often attributed to collectivist cultures. It may be felt that not showing one's negative feelings by means of a smile may help avoid conflicts between interlocutors and, therefore, threaten one's own face as well as the interlocutor's.

\subsection{Lack of eye contact}

Concerning the lack of eye contact in a face-to-face interaction, six informants believe it is important to explain the reason why directly looking at the other's eyes is avoided. For instance, informant 6 stresses that not looking into the eyes is just a sign of active listening (Gao, 1998):

Yes, because we have a word which means "to listen, not to talk", like showing respect, you know? And, sometimes, in an interview with a doctor, the patient doesn't look at him in the eye, because if he looked at him in the eye, that would mean that something is wrong, so they normally lower their gaze. And the doctor may say they don't show any respect, or something like that. But it’s not that (INF6, 38:77; female, Chinese mediator; personal communication, April 22, 2010).

Informants 3 and 5 also recall examples of misunderstandings of this specific nonverbal cue, as illustrated in the following excerpts, although related to respect rather than active listening:

Maybe, when we're mediating, it happens that many local people say [about the Chinese]: “Well, on top of that, he passes by and he doesn't even raise his head! He doesn’t even look at me! You know?” And then, you have to tell them: “Well, it’s not that he’s looking away, in fact, it's like a sign of... a kind of respect, because he doesn’t speak your language; it’s like he’s 
feeling embarrassed, as if he doesn't want to confront you” (INF5, 37:101; female, Catalan mediator; personal communication, April 22, 2010).

And [the psycho-pedagogue] also told me [about a Chinese teenager]: 'I notice he doesn’t look at me much; I've seen he hasn't looked at me much during the interview...' He had indeed looked at her, but of course he was like this [looking down] all the time, gazing down. Maybe this is very Chinese, this thing of looking down; the Chinese don't look at you directly in the eye (INF3, 35:97; female, Catalan mediator; personal communication, April 20, 2010).

In the first example, not looking into the eye is perceived as a lack of respect, whereas in the second example, the psycho-pedagogue feels as if the student were expressing rejection. In effect, the lack of eye contact was not intended to cause any of those reactions but to show respect to persons considered to be in a higher hierarchical position. According to the informants of the sample, interpreters and mediators usually warn the public service providers about these cultural differences. However, informant 20 is the only interviewee who develops this pedagogical approach towards Chinese users of public services and tries to advise them in order to avoid future misunderstanding: "I tell them that in Spain, this is impolite. I tell them that when they talk to other people, they have to look at them, I warn them” (INF20, female, Chinese mediator; personal communication, November 12, 2010).

\subsection{Haptics}

In our corpus of analysis, examples concerning other kinds of NVC are scarcer. However, there are three examples concerning haptics: two of them refer to the practice of kissing on both cheeks in Catalonia when greeting someone (INF3, INF4), and one refers to hand touch (INF5). For instance, informant 3 describes an uncomfortable situation due to the differences 
in greeting conventions, even though she also underlines it was a specific and unusual case: a psycho-pedagogue wanted to greet a fifteen-year-old boy with the customary kiss on each cheek, but he just refused exclaiming “No, no, no, no, no! Not me!”. The psycho-pedagogue was shocked and even wondered if a possible reason for that reaction was that the boy had a conflict with adults (INF3, 35:96, female, Catalan mediator; personal communication, April 20, 2010). In this specific case, without an explanation from the mediator, the psychopedagogue would have forged a possibly mistaken impression of the teenager's behaviour, when, in fact, his behaviour was culturally motivated.

Informant 15 also tries to warn teachers that Chinese do not touch each other so much and, therefore, usual gestures like a tap on someone's back or touching their arm may be misleading (INF15, 43:33, female Catalan interpreter; personal communication, July 2, 2010). These examples coincide with Axtell (1998), Bi (1998) and Torres Sánchez (1998), who also state that physical contact is scarce in Chinese culture.

\subsection{Physical appearance}

Informant 13 is the only one who recalls an example related to physical appearance and, more specifically, to clothes:

For example, children, I mean, babies, when they're born, they usually wear a lot of clothes, and Catalan babies don’t wear so many clothes, and I have to explain why... I say this is customary and sometimes I also give the reason for that: it’s because [parents] worry about their baby, they don't want him/her to catch a cold... (INF13, 26:61; female, Chinese interpreter; personal communication, May 25, 2010). 
It is true that, in China, children usually wear more clothes. Since many schools do not have heating, parents are concerned about their children catching a cold. Wrapping them up is a way of showing love and care; an implicit piece of information that would be inferred in the Chinese context. However, Catalan schools have heating and teachers may be astonished to see that Chinese children wear so many clothes. Even though it may not be a source of serious misunderstanding, it is something that may puzzle teachers. Therefore, informant 13 tries to explain the reasons for this difference in order to enhance better mutual understanding.

\subsection{Chronemics}

The next example may be related to chronemics, since it unveils different ways of conceiving time:

What also helps is changing your questions. For instance, when the doctor asks: "How long have you been like this?” the patients always say, “for a long time.” Then, I ask them: “Is a long time three days, three weeks, three months or ten years? Since when?” Then they say: “Oh, no, let me think...” Then you get the right information. This is the most difficult question in an interview. Moreover, it’s a very frequently asked question; you always have to ask, "Since when have you been feeling like that?” But they always answer, “for a long time”. Then you always have to ask more specifically, so they understand what you're asking for (INF1, 22:93; female, Chinese mediator; personal communication, March 30, 2010).

This excerpt illustrates a Chinese vaguer conception of time. Research on Chinese chronemics is scarce and therefore it is difficult to contrast this mediator's perception with previous studies. Moreover, this kind of answer may also be related to Chinese indirectness when speaking, as discussed in the second section of the present paper. However, what can 
be noted in this excerpt is mediator's role when managing the information received and trying to obtain relevant answers considering primary participants’ expectations.

\subsection{Lack of expressive cues}

The indirectness and the lack of expressive cues that some informants note, as well as the functions attributed to a smile, may be interpreted as saving face strategies, since expressing one's feelings (deception, anger, contradiction) would make one’s interlocutor feel uncomfortable and thus threaten both interlocutors' faces. This willingness to avoid uncomfortable situations is also reflected in the following example, where informant 1 explains that Chinese patients do not usually complain about pain:

Let's say it's a cultural difference. For example, in a physical examination, Chinese patients endure a lot. Therefore, they sometimes don't react enough to let the doctors know where it hurts. I already knew this, but I wasn’t sure about it until some Catalan professionals told me so; I mean, they had already observed this. I tell you now, because now I'm sure. For instance, when giving birth, or in gynaecology check-ups or in cytologies, when they extract the IUD and all that, they tell me it's very painful. And gynaecologists tell me Chinese patients don't complain at all, never, and they don't complain either when giving birth... And, then, in physical examinations, when they ask “Does it hurt here?”, they say “Maybe”, “A little”... and it does hurt! (INF1, 22:78; female, Chinese mediator; personal communication, March 30, 2010).

In this example, because of the asymmetrical power relation between doctor and patient, and since it is an interaction between strangers, similar to a transaction - the doctor offers a service that the patient needs (Cambridge, 2002) -, strategies to maintain the harmony in the 
interaction are stressed. The patient also seeks to avoid uncomfortable situations that would threaten her/his face or the doctor's. In this case, it is not a specific nonverbal cue that causes misunderstanding or confusion, but the lack of any kind of verbal or nonverbal cues that would reflect the pain the patient is experiencing.

This lack of expression of feelings in difficult situations puzzles some of the informants of the sample. They are surprised at Chinese reactions to bad news, particularly in situations where one would expect signs of sadness or hopelessness. For instance, informant 11 talks about the Chinese attitude towards death and describes the Chinese as very rational. According to her, "When they receive bad news, they accept it like saying 'Ok, it's my destiny, and I accept it’.” (INF11, 24:102, Chinese mediator; personal communication, May 7, 2010). Although she uses the third person to refer to the Chinese, informant 11 is Chinese, even though she has lived in Catalonia for more than ten years and may feel closer to Catalan reactions.

Informant 9 (41:42, male, Spanish interpreter; personal communication, May 5, 2010) also admits being surprised at the Chinese ability to accept bad news, while informant 18 comments that the "Chinese never show their anger; they are very 'British' in that sense" (INF18, 31:53; personal communication, November 16, 2010). According to informant 17, the Chinese don't usually get angry, at least in public (INF17, 30:66; personal communication, November 12, 2010).

All these reactions are clearly related to the promotion of harmony in collectivist societies, as also pointed out in the literature review.

\section{Conclusions}


Most of the informants of the sample recall situations in which factors related to NVC affect intercultural communication between public service providers and Chinese users. In summary, from the point of view of interpreters and mediators the smile and the lack of eye contact seem to be two of the most misleading nonverbal cues, as previously pointed out in Bi (1998), Sales Salvador (2003) and Sun (2010), but somehow contradicting Yang's (2007) theories. Inexpressiveness and lack of paralinguistic cues are also mentioned in the interviews and are regarded as puzzling when certain reactions from the Chinese are expected. This reinforces the theories in Clancy et al. (1996), Hall (1976) and Sales Salvador (2003). The spontaneous responses of interpreters and mediators also present examples of differences in haptics (e.g. hand touch), physical appearance and chronemics, even though these kinds of examples are more scarce. This may also indicate that differences in the domains of kinesics and paralanguage may be more noticeable in the kind of intercultural encounters where interpreters and mediators take part.

From the examples described by the informants and presented in this article, there seems to be an important correlation between Chinese NVC and saving face in Chinese interactions. Some of the most misleading nonverbal cues from the point of view of the Catalan interlocutor are facework strategies in origin. For instance, both the compensatory smile and the bitter smile try to avoid or to soften uncomfortable situations; situations that would threaten the participant's face, or even make them lose it. The lack of expressiveness and, by extension, of nonverbal cues, is also a strategy to avoid showing negative feelings, which would also make participants feel uncomfortable and, thus, lose face. The lack of eye contact is a sign of respect that especially appears in asymmetrical power relation interactions. Not showing respect, would also threaten the participant's face. These nonverbal 
cues also help to maintain harmony in the interactions and reduce the possibility of conflict; being common tendencies in collectivist cultures.

From the examples presented, we can also confirm that NVC can be a source of misunderstanding in Catalan-Chinese intercultural communication. In these cases, not only is mediation important, but it is also necessary in order to prevent misunderstanding in intercultural interactions. Therefore, even though in some contexts (e.g. court and police settings) the interpreters' role is restricted to interpreting, mediation should be recognised and accepted as a function to be assumed in specific situations, especially when misunderstanding leads to conflict.

Furthermore, considering these findings, we can affirm that having a solid knowledge of intercultural communication theories (e.g., Hall, 1976; Hofstede \& Hofstede, 2005) is essential to better understand how NVC is framed and developed in the Chinese culture. It should also be regarded as a necessary competency for both public service interpreters and intercultural mediators. In this respect, the informants' experiences point out that nonverbal cues or the absence of them can affect fluid interaction between local public service providers and Chinese users. Concerning the informants' origin, there are no specific differences in Chinese and non-Chinese interviewees' answers, since both groups provide examples of the role of NVC in intercultural communication. However, informants with longer experience do seem to be more sensitive to the influence of NVC, since among the five informants who do not pay much attention to NVC, four of them have just worked as interpreters occasionally and, three of them, for less than one year. Having received training in intercultural mediation also reinforces this awareness of NVC, as may be noted in the examples from informants 5, 6 and 17. In this regard, training can also help develop the intercultural competence mentioned before. 
Last but not least, this article also sheds light onto a topic that could certainly be further explored. On the one hand, this research has focused on Chinese NVC, but it would be very interesting to compare it to Catalan NVC and how it also affects Chinese perception of the Catalan Other. This is one of the limitations of the present study, which has only described the perception of Chinese NVC from a Catalan point of view.

On the other hand, this study relies on the perceptions of interpreters and mediators, but it would also be very enriching to contrast them with direct observation of real interactions, as well as with public service providers and Chinese users' perceptions. In this regard, both revising the theories and the results of this analysis could be the basis for future research in this field.

\section{References}

Angelelli, C. (2004). Revisiting the Interpreter's Role. Amsterdam; Philadelphia: John Benjamins.

Axtell, R. E. (1998). Gestures. The Do's and Taboos of Body Language Around the World. New York et al.: John Wiley \& Sons.

Baraldi, C. (2009). Forms of mediation: the case of interpreter-mediated interactions in medical systems. Language and Intercultural Communication, 9, 120-137. doi: 10.1080/14708470802588393

Beltrán Antolín, J. (2009). La inmigración china en Cataluña. In J. Julià-Muné (ed.), Visions de la Xina: cultura mil·lenària. Lleida: Institut d’Estudis Ilerdencs, 125-150.

Beltrán Antolín, J., Sáiz López, A. (2001). Els xinesos a Catalunya. Família, eduació i integració. Barcelona: Fundació Jaume Bofill; Editorial Altafulla.

Bi，J. [毕继万] (1998). Kuawenhua Fei-yuyan Jiaoji [跨文化非语言交际. Beijing: Waiyu Jiaoxue yu Yanjiu Chubanshe [外语教学与研究出版社].

Birdwhistell, R. (1970). Kinesics and context: Essays on body motion communication. Philadelphia: University of Pennsylvania Press.

Bolden, G. (2000). Toward Understanding Practices of Medical Interpreting: Interpreters' Involvement in History Taking. Discourse Analysis, 2, 387-419. doi: $10.1177 / 1461445600002004001$

Bond, M. H. (1991). Beyond the Chinese Face. Insights from Psychology. Hong Kong; Oxford; New York: Oxford University Press. 
Bond, M. H. (1993). Emotions and their expression in Chinese culture. Journal of Nonverbal Behavior, 17, 245-262. doi: 10.1007/BF00987240

Cambridge, J. (1999). Information loss in Bilingual Medical Interviews through an Untrained Interpreter. The Translator, 5, 201-219. Retrieved from: https://www.stjerome.co.uk/tsa/abstract/119/

Cambridge, J. (2002). Interlocutor roles and the pressures on interpreters. In C. ValeroGarcés \& G. Mancho Barés (eds.). Traducción e Interpretación en los Servicios Públicos. Nuevas necesidades para nuevas realidades. Community interpreting and translating: new needs for new realities. Madrid: Servicio de Publicaciones de la Universidad de Alcalá, 119124.

Chen, J. [陈建民] (1987). Shuohua de yishu [说话的艺术]. Beijing: Yuwen chubanshe [语文 出版社].

Cirillo, L. (2010). Managing affect in interpreter-mediated institutional talk: examples from the medical setting. Jostrans, 14, 55-79. Retrieved from: http://www.jostrans.org/issue14/art_cirillo.pdf

Clancy, P., Thompson, S., Suzuki, R, Tao, H. (1996). The conversational use of reactive tokens in English, Japanese and Mandarin. Journal of Pragmatics, 26, 355-387. doi: 10.1016/0378-2166(95)00036-4

Davidson, B. (2000). The Interpreter as Institutional Gatekeeper: The Social-linguistic Role of Interpreters in Spanish-English Medical Discourse. Journal of Sociolinguistics, 4, 379405. doi: 10.1111/1467-9481.00121

Fadiman, A. (2012). The Spirit Catches You and You Fall Down. A Hmong Child, Her American Doctors, and the Collision of Two Cultures. New York: Farrar, Straus and Giroux.

Gao, G. (1998). “Don’t take my word for it.” - Understanding Chinese speaking practices. International Journal of Intercultural Relations, 22, 163-186. doi: 10.1016/S01471767(98)00003-0

Gao, G., Ting Toomey, S. (1998). Communicating effectively with the Chinese. Thousand Oaks, California: Sage.

Guerrero, L. K., Floyd, K. (2006). Nonverbal communication in close relationships. New Jersey: Lawrence Erlbaum Associates.

Hale, S, (2001). How are Courtroom Questions Interpreted? An Analysis of Spanish Interpreters' Practices. In I. Mason (ed.) Triadic Exchanges. Studies in Dialogue Interpreting. Manchester: St. Jerome, 21-50.

Hale, S. (2002). How faithfully do court interpreters render the style of non-English speaking witness' testimony? A data-based study of Spanish-English bilingual proceedings". Discourse Studies, 4, 25-47. doi: 10.1177/14614456020040010201

Hall, S. (1976). Beyond culture. New York: Doubleday.

Hickson, M., Stacks, D. W., Moore, N. (2004). Nonverbal communication: studies and applications. Los Angeles: Roxbury.

Hofstede, G. (1980). Culture's consequences: International differences in work-related values. Beverly Hills, California: Sage. 
Hofstede, G. (1991). Cultures and organizations. Berkshire, England: McGraw Hill.

Hofstede, G.; Hofstede, G. J. (2005). Cultures and organizations: software of the mind. New York: McGraw-Hill.

Hu, H. (1944). The Chinese concepts of “face”. American Anthropologist, 46, 45-64. doi: 10.1525/aa.1944.46.1.02a00040

Hwang, K. (1987). Face and Favor: The Chinese Power Game. The American Journal of Sociology, 92 (4), 944-974. doi: 10.1086/228588

Iglesias Fernández, E. (2010). Verbal and nonverbal concomitants of rapport in health care encounters: implications for interpreters. Jostrans, 14, 216-228. Retrieved from: http://www.jostrans.org/issue14/art_iglesias.pdf

Knapp, M. L., Hall, J. A. (2010). Nonverbal Communication in Human Interaction. Boston, MA: Wadsworth, Cengage Learning.

Malandro, L. A., Barker, L. L. (1983). Nonverbal Communication. Reading, MA: AddisonWesley.

Mason, I.; Stewart, M. (2001). Interactional Pragmatics, Face and the Dialogue Interpreter. In Ian Mason (ed.). Triadic Exchanges. Studies in Dialogue Interpreting. Manchester: St. Jerome Publishing, 51-70.

Mehrabian, A. (1981). Silent Messages: Implicit Communication of Emotions and Attitudes. Belmont, CA: Wadsworth.

Philpott, J. S. (1983). The Relative Contribution to Meaning of Verbal and Nonverbal Channels of Communication: A Meta-Analysis. (Unpublished master's thesis). University of Nebraska.

Pöllabauer, S. (2004). Interpreting in asylum hearings. Issues of role, responsibility and power. Interpreting, 6, 143-180.

Pöllabauer, S. (2006). “Translation culture” in interpreted asylum hearings. In A. Pym, M. Shlesinger, Z. Jettmarová (eds.) Sociocultural Aspects of Translating and Interpreting. Amsterdam; Philadelphia: John Benjamins, 151-162.

Raga Gimeno, F. (2003). Para un análisis empírico de las interacciones comunicativas interculturales. In Grup CRIT (ed.) Claves para la comunicación intercultural. Análisis de interacciones comunicativas con inmigrantes. Castelló de la Plana: Universitat Jaume I, 1735.

Raga Gimeno, F. (2005). Comunicación y cultura. Propuestas para el análisis transcultural de las interacciones comunicativas cara a cara. Madrid; Frankfurt: Iberoamericana; Vevuert.

Raga Gimeno, F. (2009). Atención sanitaria a la población origen chino. Salud y Cultura. Portal informativo para la mediación intercultural y la interpretación en el ámbito sanitario. In Grupo CRIT. Universitat Jaume I. Retrieved from: http://www.saludycultura.uji.es/china.php

Raga Gimeno, F., Sánchez López, E. (1999). La problemática de la toma de turnos en la comunicación intercultural. In J. Fernández González et al. (eds.) Lingüística para el siglo XXI, vol. I. Salamanca: Universidad de Salamanca, 1349-1357. 
Ramsey, S. (1984). Double vision: Nonverbal behavior: East and west. In A. Wolfgang (ed.): Nonverbal Behavior: Perspectives, Applications, Intercultural Insights. Seattle, Hogrefe \& Huber Publishers, 139-167.

Sales Salvador, D. (2003). Interacción comunicativa intercultural con inmigrantes procedentes de la cultura china. In Grup CRIT (ed.) Claves para la comunicación intercultural. Análisis de interacciones comunicativas con inmigrantes. Castelló de la Plana: Universitat Jaume I, 123-148.

Scollon R., Scollon, S. (1995). Intercultural Communication: A Discourse Approach. Oxford: Blackwell.

Sperber, D., Wilson, D. (1995). Relevance: Communication and Cognition. Oxford et al.: Basil Blackwell.

Sun, J. K. (2010). Deciphering the Chinese Smile: The Importance of Facial Expressions in Linguistic Communication. Cross-sections, VI, 105-120.

Torres Sánchez, A. E. (2010). Signos no verbales chinos y españoles: estudio contrastivo. (Unpublished master's thesis). Alcalá University.

Triandis, H. C., Brislin, R., Hui, H. C. (1988). Cross-cultural training across the individualism-collectivism divide. International Journal of Intercultural Relations, 12, 269289. doi: 10.1016/0147-1767(88)90019-3

Vargas-Urpi, M. (2012). La interpretació als serveis públics i la mediació intercultural amb el col-lectiu xinès a Catalunya. Doctoral dissertation. Universitat Autònoma de Barcelona. Retrieved from: http://www.tdx.cat/handle/10803/96486

Vargas-Urpi, M. (2013). ISP y/o mediación intercultural: la realidad de los profesionales que trabajan en el contexto catalán. Cuadernos ALDEEU, 25, 131-164.

Wadensjö, C. (1998). Interpreting as interaction. New York: Longman.

Wadensjö, C. (2001). Interpreting in crisis. The interpreter's Position in Therapeutinc Encounters. In I. Mason (ed.) Triadic Exchanges. Studies in Dialogue Interpreting. Manchester: St. Jerome, 71-85.

Wood, J. (2013). Interpersonal Communication: Everyday Encounters. Boston, MA: Wadsworth, Cengage Learning.

Yang, P. (2007). Nonverbal Affiliative Phenomena in Mandarin Chinese Conversation. Journal of Intercultural Communication, vol. 15. Retrieved from: http://www.immi.se/intercultural/nr15/yang.htm

Yang, P. (2011). Nonverbal aspects of turn taking in Mandarin Chinese interaction. Chinese Language and Discourse, 2, 99-130. doi: 10.1075/cld.2.1.09yan

Young, L. (1994). Crosstalk and Culture in Sino-American Communication. Cambridge: Cambridge University Press. 